Technical Report

\title{
Development of novel green and biocomposite materials: Tensile and flexural properties and damage analysis using acoustic emission
}

\author{
Alencar Bravo ${ }^{a, 1}$, Lotfi Toubal ${ }^{a, *}$, Demagna Koffi ${ }^{a, 2}$, Fouad Erchiqui ${ }^{b, 3}$ \\ ${ }^{a}$ Laboratory of Mechanics and Eco-Materials, University of Quebec at Trois-Rivières, 3351, boul. des Forges, C.P. 500, Trois-Rivières, Québec G9A 5H7, Canada \\ ${ }^{\mathrm{b}}$ Laboratory of Biomaterials, University of Quebec at Abitibi-Témiscamingue, 445, boul. de l'Université, Rouyn-Noranda, Quebec J9X 5E4, Canada
}

\section{A R T I C L E I N F O}

\section{Article history:}

Received 21 June 2014

Accepted 9 October 2014

Available online 30 October 2014

\begin{abstract}
A B S T R A C T
A new green composite made of natural polyethylene (NPE) has never been produced using short birch fibers and compared with others biocomposites with matrices of linear low-density polyethylene (LLDPE) and high-density polyethylene (HDPE). Versions with and without a coupling agent (CA) in fiber ratios of $10,20,30$ and $40 \mathrm{wt} \%$ were produced. Tensile and 3-point flexural tests were conducted to measure the mechanical properties of the composites, and acoustic-emission testing was used to measure the evolution of damage caused by irreversible changes in the materials in correlation with an analysis of the damage modes. It was concluded that the extent of the damage and the contribution of each damage mode depend on the material, the test performed and, especially the presence of a CA. The results prove that the choice of composite for a particular application must be a judicious one and should consider not only the mechanical properties but also the damage processes of the composite, which may be crucial for longterm applications.
\end{abstract}

(c) 2014 Elsevier Ltd. All rights reserved.

\section{Introduction}

It is often a difficult task, therefore, to reconcile the long-term utilization of a composite with minimal environmental impact at the end of the product's life cycle. Nevertheless, in recent years, we have seen an increase in government awareness and public pressure that has resulted in the use of more eco-friendly and sustainable materials.

The term 'biocomposite' is employed when natural fibers are used as an environmentally friendly alternative to composites with traditional fibers. The advantages of natural fibers include certain notable properties, such as low density, high specific strength, enhanced energy recovery, $\mathrm{CO}_{2}$ neutrality after burning, easy processing, bio-degradability and low cost $[1,2]$. However, these biocomposites still depend on oil to some extent and can cause waste problems because of the use of non-degradable polymer matrices.

Among other ecological solutions, a noteworthy class of composites with structurally sound properties has been developed:

\footnotetext{
* Corresponding author. Tel.: +1 8193765011x3970.

E-mail addresses: alencar.soares.bravo@uqtr.ca (A. Bravo), lotfi.toubal@uqtr.ca (L. Toubal), koffi@uqtr.ca (D. Koffi), fouad.erchiqui@uqat.ca (F. Erchiqui).

1 Tel.: +1 8193765011×3949.

2 Tel.: +1 8193765011x3910

3 Tel: +1 8197620971
}

polyethylene (PE) with birch fiber. PE is the most affordable thermoplastic with the highest share of production of any polymer type, representing $29.1 \%$ of the world's plastic production [3]. PE is obtained through the polymerization of ethylene $\left(\mathrm{C}_{2} \mathrm{H}_{4}\right)$, which produces macromolecules consisting of a repeating monomer unit $\left(\mathrm{CH}_{2}-\mathrm{CH}_{2}\right)$. In addition, the most widely available natural filler in province of Québec is birch fiber. Because this hardwood tree grows in cool areas with abundant precipitation, the region contains approximately $50 \%$ of the growing stock volume of yellow birch in North America [4]. The combination of these two materials results in an eco-solution in the form of a biocomposite that is simple to manufacture and, consequently, should be very affordable.

The most affordable variant of PE is linear low-density polyethylene (LLDPE), which has the highest ductility and the poorest Young modulus and mechanical strength at room temperature among all semi-crystalline polymers [5]. Studies of the mechanical properties of LLDPE biocomposites with aspen fibers have been conducted by $\mathrm{Gu}$ and Raj et al. [6,7]. In a recent work, Mijiyawa et al. $[8,9]$ studied the thermal degradation of LLDPE/birch but did not analyze the resulting mechanical damage. More recently, Lafia-Araga et al. [10] has tested red balau fibers using various thermal treatments at the fiber level and has observed an increase in the matrix/fiber adhesion that improved the mechanical properties of the material. It is now acknowledged that the use of a coupling agent (CA) is essential to improve the overall quality of biocomposites with such constituents [11-13]. 
The properties of PE are determined largely by the arrangement of the polymer chain. Properties such as the crystalline melting point, the density, the hardness and the permeability are determined by the type, number and distribution of short-chain branches, whereas the viscosity is affected primarily by long-chain branches [14,15]. High-density polyethylene (HDPE) is a linear polymer with no short branching but and a small fraction of long branches [16]. HDPE thus possesses improved mechanical properties for a small price increase. Some biocomposites have been studied using HDPE as the matrix. Migneault et al. [17] have studied the properties of the polymeric matrix impregnated with white birch fibers under various loads using a rheometer. They concluded that not only were the mechanical properties affected by the fiber weight, but the melting properties were affected as well. Raj and Kokta [18] have arrived at similar conclusions using aspen fibers. The use of a CA is also strongly indicated. Lu et al. [19] have provided evidence that of the various CAs they tested, maleated polyethylene (MAPE) was the best option. In addition, Colom et al. [20] have demonstrated the 'bridging' effect of MAPE using scanning electron microscopy (SEM) images. Adhikarya et al. [21] have investigated the differences in stability, mechanical properties and microstructure between recycled and virgin HDPE using fibers of Pinus radiata. The results were very encouraging from an ecological perspective because they demonstrated that regardless of whether virgin or recycled HDPE was used, the mechanical properties of the biocomposite were the same.

Nevertheless, there are two aspects in which the literature lacks data regarding these composites: (1) the improvement of the green nature of composites with natural fiber content below 50 wt\% (i.e., with one or more thermoplastics as the major constituent of the matrix) and (2) a thorough analysis of the progression of mechanical damage mechanisms within the composites caused by the application of external stresses in various scenarios.

To address point 1 , green composites can be created using a biosourced matrix and natural fibers [22]. Among the green matrix materials that are available, polylactides (PLAs), polyhydroxyalkanoates (PHAs) and bio polyvinyl chlorides (PVCs) are of particular interest [23]. These materials bear no similarity to PE; however, in 2010, Braskem (America's top producer of thermoplastic [24]) developed a "natural (green) polyethylene" (NPE) sourced entirely from sugarcane, which was a technological breakthrough. We were therefore able to fabricate a green family of composites using this material for comparison with composites based on PE. To produce the biopolymer, Braskem converts sugarcane-derived ethanol into ethylene using a process known as ethanol dehydration. This process converts $99 \%$ of the ethanol carbon into polyethylene [25]. Contrary to the petroleum-based PE process, the sugarcane $\mathrm{CO}_{2}$ remains fixed during the complete life cycle.

According to Braskem, green PE presents ecological advantages over the life cycle assessment (LCA) when compared to the conventional PE: this polymer captures 2.5 tonnes of $\mathrm{CO}_{2}$ per ton of product [26]. Today, several end users are using NPE (e.g.: Johnson \& Johnson, Nestle, Toyota, Danone, P\&G) [26]. To our knowledge, a green composite based on NPE has never before been produced using short birch fibers.

The advantages of increasing the fiber ratio in a NPE composite are twofold: (1) Price benefit for using a widely available material (in addition, these fiber can obtained from waste) and (2) The enlargement of application range due to the increase in the mechanical properties. Furthermore, there is no record of the effect of the use of a CA on the material behavior of such green composites.

To address point 2, tensile and 3-point flexural tests can be conducted to measure the mechanical properties and the mechanisms and evolution of the damage caused by irreversible changes in the material under study. The acoustic-emission (AE) technique is generally defined as elastic energy spontaneously released during local, dynamic and irreversible changes of the (micro)structure of the materials [27]. AE is also observed during phase transformations and plastic deformations [27]. With this definition is important to note that damage (irreversible change) due to stress can occur without plasticity. In this case, AE becomes most useful when not only the progression but the nature of the mechanism that originated each sound wave can be tracked, specially dealing with materials where the damage process is not well understood. AE testing can be used to characterize the evolution and competition of the various damage modes in a material.

The damage model associated with the mechanical processes proposed in this study is based on the model introduced by Kachanov [28], which assumes that the damage to a material can be interpreted in terms of the density of defects in that material. Mehan and Mullin [29] was the first researcher to correlate a damage mechanism with an acoustic signature (AS). Damage-mechanism analysis has traditionally been performed using simple investigative histograms of cumulative hits versus amplitude [30,31]. However, this methodology can be inaccurate for complex materials [32], especially biological materials (i.e., cellular structures assembled through a hierarchical process in nature) using thermoplastics (with strong damping properties) [33,34]. In this case, a more complex analysis is recommended, specifically, the use of fuzzy logic systems [35-37], which have the ability to detect clusters among data even when the boundaries between groups overlap [38]. The use of three known parameters for damage-mode identification in the PE/birch composite family is proposed [34]: the burst amplitude, the counts and the duration. Three families of composites using natural birch fibers and matrices of LLDPE, HDPE and NPE were developed. For each matrix, we produced versions with and without a CA in fiber ratios of $10,20,30$ and $40 \mathrm{wt} \%$. Thus, 54 varieties of composites totaling 270 specimens were produced in this comprehensive study.

This paper is organized as follows. First, the materials, methodology and procedures of experimental testing are described. Second, the mechanical behavior and properties of the various composites as determined from the tensile and flexural testing are discussed and compared. Third, an AE damage analysis is presented based on the results of tensile and flexural testing and the results are discussed. Finally, the previous results are correlated with SEM images before presenting the final conclusions.

\section{Materials and experimental testing}

\subsection{Materials}

Industrial short fibers (thermomechanical pulping, 35 mesh size) of yellow birch (Betula alleghaniensis) were used in this experiment. The fibers were produced by the Lignocellulosic Materials Research Centre, Trois-Rivières (Canada), and dried at $60^{\circ} \mathrm{C}$ in an air-circulating oven for $24 \mathrm{~h}$ before use.

The three thermoplastic matrices that were used were LLDPE (Novacor ${ }^{\circledR}$ HI-0753-H), donated by NOVA Chemicals; HDPE (Sclair ${ }^{\circledR}$ 2909), donated by NOVA Chemicals; and NPE (version HDPESHA7260), donated by Braskem. MAPE (maleated polyethylene, G2010), supplied by Eastman Chemical Company (Kingsport, TN, USA), was used as the CA. The content of maleic acid grafts was $1.5 \%$ with a molecular weight of 15,000 . The CA chemical composition leads to the formation of chemical bridges between the natural fibers and the PE matrix. The use of CA in quantities beyond $4 \mathrm{wt} \%$ can lead to self-entanglement among CA chains rather than with the polymer matrix [39]. For this reason, CA was used at $3 \mathrm{wt} \%$.

All specimens were prepared using a two-roll mill (Thermon C.W. Brabender, Model T-303) with a 0.6 gear ratio. The grains of 
the matrix were melted on rollers at $170{ }^{\circ} \mathrm{C}$, and the fiber was subsequently added at the desired weight ratio $(0,10,20,30$ or $40 \mathrm{wt} \%$ ). Specimens were producing using molding process at a temperature of $205^{\circ} \mathrm{C}$ using a hydraulic press for $20 \mathrm{~min}$ at a pressure of $10 \mathrm{MPa}$. Each specimen weight was measured with a precision balance and those with more than $1 \%$ of void fraction were rejected.

\subsection{Experimental testing}

A monotonic tensile test was conducted at room temperature in accordance with ASTM: D3039 specifications. The specimens had a 4 by $10-\mathrm{mm}$ rectangular cross section with an overall length of $150-\mathrm{mm}$.For each test condition, five specimens were tested, and the average value was tabulated. A 3-point flexural test was then performed in accordance with ASTM: D790. In this case, the specimens had a rectangular cross section of 12.7 by $3.2 \mathrm{~mm}$ with an overall length of $127-\mathrm{mm}$. Five composite specimens were tested for each sample.

Both tests were carried outperformed using an Instron model LM-U150 electromechanical testing machine. In tensile mode (Fig. 1a), it was operated with a $150-\mathrm{kN}$ load cell, and a $50-\mathrm{mm}$ extensometer was connected to the data-acquisition system and fixed to the gauge-length section of the specimen to record variations in strain. In flexural mode (Fig. 1b), a 10-kN cell was used because a much lower force on the specimen is required for flexural testing. The crosshead speed in both tests was $1 \mathrm{~mm} / \mathrm{min}$ to reduce dynamical effects.

The AE measurements were conducted using devices provided by the Physical Acoustics Corporation (PAC), which were equipped with two PCI cards. Two sensors (Micro-80 PAC, wideband 100$1000 \mathrm{kHz}$ ) were mounted on the surface of the test specimen with a spacing of $70 \mathrm{~mm}$. An acoustic threshold level of $35 \mathrm{~dB}$ was used to filter out the background noise. A silicone adhesive gel was employed as a CA between the sensors and the specimen. Before each test, the quality of the coupling was verified using a Nielsen-Hsu pencil-lead break [40].

\section{Mechanical results and discussion}

\subsection{Tensile test}

Fig. 2 presents the stress-strain curves recorded during the monotonic tensile testing of specimens of pure LLDPE (2a), HDPE (2b) and NPE (2c). The data show that the behaviors of the different matrices are approximately similar; however, NPE was the only material to break within the limits of our tensile testing machine.

All results of tensile testing are summarized in Table 1 . The manufacturing protocol used in this study demonstrates good measurement reproducibility with a low standard deviation. Pure LLDPE has a Young's modulus of $1.16 \mathrm{GPa}$ and a maximum strength of $21.11 \mathrm{MPa}$. Compared with the pure matrix, the
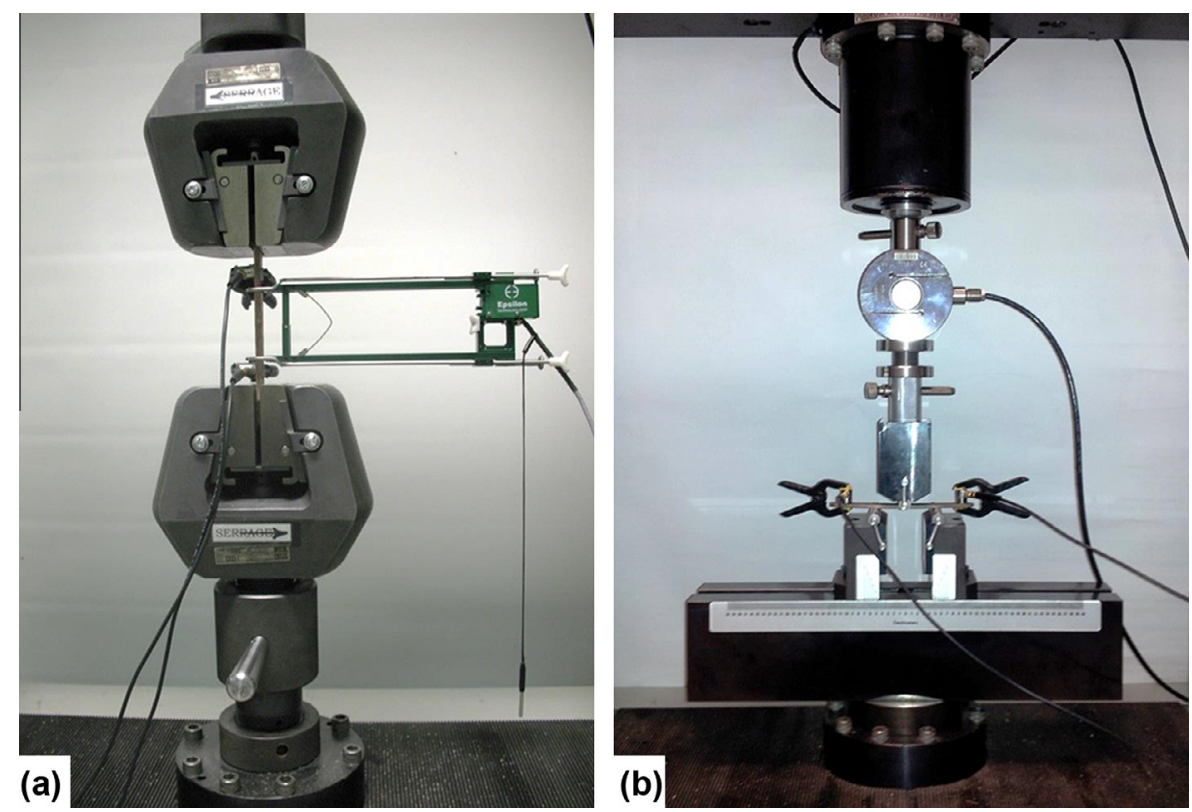

Fig. 1. Mechanical tests: (a) tensile testing and (b) flexural testing.
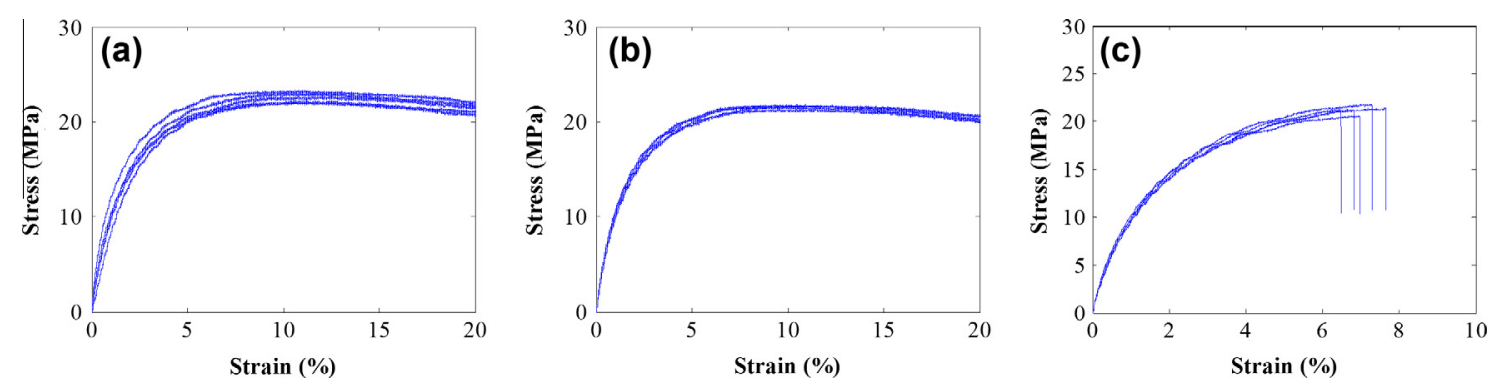

Fig. 2. Tensile testing curves for the pure matrix specimens (a) LLDPE, (b) HDPE and (c) NPE. 
Table 1

Summary of tensile properties.

\begin{tabular}{|c|c|c|c|c|c|c|c|c|c|c|c|}
\hline \multirow[t]{2}{*}{ Matrix used (wt\%) } & \multirow[t]{2}{*}{ Fiber weight (wt\%) } & \multirow[t]{2}{*}{ Coupling agent (wt\%) } & \multicolumn{3}{|c|}{ Young modulus (GPa) } & \multicolumn{3}{|c|}{ Maximum stress (MPa) } & \multicolumn{3}{|c|}{ Strain at failure } \\
\hline & & & Mean value & STD DEV & $\mathrm{CoV}$ & $\sigma \max (\mathrm{MPA})$ & STD DEV & $\mathrm{CoV}$ & $d(\%)$ & STD DEV & $\mathrm{CoV}$ \\
\hline LLDPE & 0 & - & 1.16 & 0.20 & 0.17 & 21.11 & 2.56 & 0.12 & - & - & \\
\hline LLDPE & 10 & 0 & 1.39 & 0.25 & 0.18 & 25.62 & 1.44 & 0.06 & 15.46 & 3.60 & 0.23 \\
\hline LLDPE & & 3 & 1.90 & 0.28 & 0.15 & 28.87 & 1.37 & 0.05 & 16.04 & 4.01 & 0.25 \\
\hline LLDPE & 20 & 0 & 2.18 & 0.24 & 0.11 & 31.87 & 1.12 & 0.04 & 11.39 & 1.77 & 0.16 \\
\hline LLDPE & & 3 & 2.78 & 0.24 & 0.09 & 35.28 & 1.30 & 0.04 & 9.02 & 0.88 & 0.10 \\
\hline LLDPE & 30 & 0 & 2.46 & 0.23 & 0.09 & 33.04 & 1.85 & 0.06 & 5.90 & 0.92 & 0.16 \\
\hline LLDPE & & 3 & 3.30 & 0.20 & 0.06 & 40.09 & 1.59 & 0.04 & 4.35 & 0.53 & 0.12 \\
\hline LLDPE & 40 & 0 & 3.30 & 0.12 & 0.04 & 35.59 & 2.79 & 0.08 & 2.99 & 0.66 & 0.22 \\
\hline LLDPE & & 3 & 3.82 & 0.07 & 0.02 & 37.86 & 4.21 & 0.11 & 2.12 & 0.27 & 0.13 \\
\hline HDPE & 0 & - & 1.27 & 0.07 & 0.06 & 22.00 & 0.86 & 0.04 & - & & \\
\hline HDPE & 10 & 0 & 1.92 & 0.19 & 0.10 & 27.34 & 1.99 & 0.07 & 3.63 & 0.64 & 0.18 \\
\hline HDPE & & 3 & 1.98 & 0.03 & 0.02 & 27.78 & 1.56 & 0.06 & 3.40 & 1.18 & 0.35 \\
\hline HDPE & 20 & 0 & 2.18 & 0.19 & 0.09 & 29.79 & 1.47 & 0.05 & 5.07 & 0.68 & 0.13 \\
\hline HDPE & & 3 & 2.14 & 0.04 & 0.02 & 31.05 & 0.86 & 0.03 & 5.23 & 1.21 & 0.23 \\
\hline HDPE & 30 & 0 & 2.94 & 0.13 & 0.04 & 34.04 & 1.13 & 0.03 & 3.50 & 0.39 & 0.11 \\
\hline HDPE & & 3 & 2.89 & 0.06 & 0.02 & 36.88 & 1.10 & 0.03 & 4.60 & 0.10 & 0.02 \\
\hline HDPE & 40 & 0 & 4.30 & 0.34 & 0.08 & 36.01 & 3.03 & 0.08 & 1.74 & 1.01 & 0.58 \\
\hline HDPE & & 3 & 4.48 & 0.04 & 0.01 & 45.12 & 1.92 & 0.04 & 2.44 & 0.50 & 0.20 \\
\hline NHDPE & 0 & - & 1.17 & 0.17 & 0.15 & 21.39 & 0.34 & 0.02 & 7.80 & 0.51 & 0.07 \\
\hline NHDPE & 10 & 0 & 1.93 & 0.16 & 0.08 & 26.89 & 1.03 & 0.04 & 4.00 & 0.94 & 0.24 \\
\hline NHDPE & & 3 & 1.99 & 0.18 & 0.09 & 27.21 & 0.55 & 0.02 & 3.19 & 0.31 & 0.10 \\
\hline NHDPE & 20 & 0 & 2.43 & 0.17 & 0.07 & 29.67 & 1.62 & 0.05 & 3.70 & 0.39 & 0.11 \\
\hline NHDPE & & 3 & 2.33 & 0.06 & 0.03 & 29.92 & 1.02 & 0.03 & 2.89 & 0.38 & 0.13 \\
\hline NHDPE & 30 & 0 & 3.04 & 0.29 & 0.10 & 33.47 & 3.13 & 0.09 & 2.18 & 0.77 & 0.35 \\
\hline NHDPE & & 3 & 3.50 & 0.13 & 0.04 & 40.60 & 1.37 & 0.03 & 2.50 & 0.08 & 0.03 \\
\hline NHDPE & 40 & 0 & 3.86 & 0.07 & 0.02 & 32.68 & 0.40 & 0.01 & 1.78 & 0.40 & 0.22 \\
\hline NHDPE & & 3 & 4.57 & 0.20 & 0.04 & 46.45 & 1.74 & 0.04 & 2.70 & 0.34 & 0.13 \\
\hline
\end{tabular}

Young's modulus increased by $19.83 \%, 87.93 \%, 112.07 \%$ and $184.48 \%$ for biocomposites with fiber contents of $10,20,30$ and $40 \mathrm{wt} \%$, respectively. In the same order, the ultimate strength increased by $21.36 \%, 50.97 \%, 56.51 \%$ and $68.58 \%$. These results demonstrate an improvement in the mechanical properties of the material even without the use of a CA. However, as the fiber content increases, the biocomposite loses ductility, as indicated by the decrease in the strain rate at failure.

When analyzing only the effect of adding a CA to a biocomposite without one, the data indicate improvements in the Young's modulus by $36.09 \%, 27.52 \%, 34.15 \%$ and $15.69 \%$ for samples with fiber contents of 10, 20, 30 and $40 \mathrm{wt} \%$, respectively. The maximum stress also increased compared with the biocomposite without CA, by $12.69 \%, 10.70 \%, 21.34 \%$ and $6.39 \%$, respectively. Surprisingly, the 40-wt\% sample exhibited both the smallest improvement in Young's modulus and the lowest increase in maximum stress with the addition of the CA.

When the pure HDPE matrix is compared with the pure LLDPE matrix, the data indicate an increase of $9.48 \%$ in the Young's modulus of the HDPE over that of the LLDPE and a similar increase of $4.22 \%$ in the maximum stress. Similar to the LLDPE-based biocomposites, an increase in the fiber content reduced the ductility of the material while increasing the Young's modulus and the ultimate strength (c.f. Table 1). For the specimens without a CA, in increasing order of fiber content, the Young's modulus increased by $51.18 \%, 71.65 \%, 131.50 \%$ and $238.58 \%$, compared with that of the pure HDPE matrix specimens. In the same order, the maximum stress increased by $24.27 \%, 35.41 \%, 54.73 \%$ and $63.64 \%$, compared with the pure matrix specimens.

Adding a CA to an HDPE biocomposite has a minimal effect on the Young's modulus, resulting in increases of only $3.13 \%$, $-1.83 \%,-1.70 \%$ and $4.19 \%$ for the specimens with fiber contents of $10,20,30$ and $40 \mathrm{wt} \%$, respectively. The addition of the CA improved the maximum stress, however, with increases of 1.58 , 4.06, 7.70 and, remarkably, $20.19 \%$ (in the same order as above) compared with the corresponding specimens without a CA.
When the pure NPE matrix specimen is compared with the pure HDPE matrix specimen, the data indicate that the Young's modulus of the green composite is $7.87 \%$ lower and that its maximum strength is $2.77 \%$ lower; however, compared with the pure LLDPE matrix specimen, the Young's modulus is $0.86 \%$ higher, and the maximum strength is $1.33 \%$ higher.

The NPE matrix was found to perform well, exhibiting a marked increase in the mechanical properties as the fiber content was increased. Compared with the pure matrix, the samples without a CA and with fiber contents of 10, 20, 30 and $40 \mathrm{wt} \%$ exhibited improvements of $64.96 \%, 107.69 \%, 159.83 \%$ and $229.91 \%$ in the Young's modulus, respectively. The maximum strength was improved by $26.89 \%, 38.71 \%, 56.47 \%$ and $52.78 \%$, in the same order.

The effect of the CA on the Young's modulus was not monotonic, but the Young's modulus did generally improve with higher fiber content, exhibiting changes of $7.89 \%,-7.94 \%, 24.60 \%$ and $26.39 \%$ compared with the corresponding sample without a CA for specimens with fiber contents of $10,20,30$ and $40 \mathrm{wt} \%$, respectively. The maximum stress exhibited similar behavior, i.e., it increased by $5.82 \%, 3.02 \%, 59.02 \%$ and $121.97 \%$ compared.

\subsection{Flexural test}

As shown in Table 2, the manufacturing protocol used in this work demonstrated good measurement reproducibility with a low standard deviation. The increase in the Young's moduli of the LLDPE-based composites without a CA was not linear with the increase in fiber content. Initially, the modulus rose rapidly at a fiber content of $10 \mathrm{wt} \%$, increasing by $74.09 \%$, and for $20 \mathrm{wt} \%$, it increased by $135.12 \%$. This increase was nearly linear. However, at $30 \mathrm{wt} \%$ and beyond, the increase was no longer linear; the modulus increased by $159.60 \%$ at $30 \mathrm{wt} \%$, and then, at $40 \mathrm{wt} \%$, there was a $4.9 \%$ decrease in improvement, corresponding to an improvement of only $154.7 \%$ over the pure matrix. Regarding the maximum stress, the data indicate nearly linear improvement; the specimens with fiber contents of less than $20 \mathrm{wt} \%$ exhibited a 
Table 2

Summary of flexural properties.

\begin{tabular}{|c|c|c|c|c|c|c|c|c|c|c|c|}
\hline \multirow[t]{2}{*}{ Matrix used (wt\%) } & \multirow[t]{2}{*}{ Fiber Weight (wt\%) } & \multirow[t]{2}{*}{ Coupling agent (wt\%) } & \multicolumn{3}{|c|}{ Young modulus (Gpa) } & \multicolumn{3}{|c|}{ Maximum Stress (Mpa) } & \multicolumn{3}{|c|}{ Strain at failure } \\
\hline & & & Mean Value & STD DEV & $\mathrm{CoV}$ & $\sigma \max (\mathrm{MPA})$ & STD DEV & $\mathrm{CoV}$ & $d(\%)$ & STD DEV & $\mathrm{CoV}$ \\
\hline LLDPE & 0 & 0 & 1.02 & 0.07 & 0.07 & 24.97 & 0.58 & 0.02 & - & - & \\
\hline LLDPE & 10 & 0 & 1.78 & 0.14 & 0.08 & 37.89 & 2.46 & 0.06 & - & - & \\
\hline LLDPE & & 3 & 1.76 & 0.11 & 0.06 & 39.39 & 0.70 & 0.02 & - & - & \\
\hline LLDPE & 20 & 0 & 2.40 & 0.13 & 0.05 & 50.48 & 0.91 & 0.02 & - & - & \\
\hline LLDPE & & 3 & 2.32 & 0.16 & 0.07 & 50.22 & 1.06 & 0.02 & - & - & \\
\hline LLDPE & 30 & 0 & 2.65 & 0.31 & 0.12 & 53.91 & 4.95 & 0.09 & 8.35 & 0.56 & 0.07 \\
\hline LLDPE & & 3 & 2.91 & 0.29 & 0.10 & 61.29 & 2.02 & 0.03 & 7.52 & 0.30 & 0.04 \\
\hline LLDPE & 40 & 0 & 2.61 & 0.16 & 0.06 & 61.84 & 1.23 & 0.02 & 6.32 & 0.59 & 0.09 \\
\hline LLDPE & & 3 & 3.86 & 0.36 & 0.09 & 70.67 & 2.67 & 0.04 & 3.98 & 0.18 & 0.05 \\
\hline HDPE & 0 & 0 & 0.88 & 0.06 & 0.07 & 27.08 & 0.03 & 0.00 & - & - & \\
\hline HDPE & 10 & 0 & 1.61 & 0.06 & 0.04 & 40.27 & 0.05 & 0.00 & - & - & \\
\hline HDPE & & 3 & 1.26 & 0.18 & 0.14 & 38.52 & 0.11 & 0.00 & - & - & \\
\hline HDPE & 20 & 0 & 1.92 & 0.05 & 0.03 & 46.24 & 0.04 & 0.00 & 8.78 & 0.44 & 0.05 \\
\hline HDPE & & 3 & 1.68 & 0.14 & 0.08 & 45.70 & 0.19 & 0.00 & 10.13 & 0.14 & 0.01 \\
\hline HDPE & 30 & 0 & 2.07 & 0.18 & 0.09 & 47.13 & 0.04 & 0.00 & 8.90 & 0.29 & 0.03 \\
\hline HDPE & & 3 & 2.02 & 0.15 & 0.07 & 51.72 & 0.14 & 0.00 & 8.31 & 0.51 & 0.06 \\
\hline HDPE & 40 & 0 & 3.21 & 0.27 & 0.08 & 58.52 & 0.25 & 0.00 & 4.53 & 0.39 & 0.09 \\
\hline HDPE & & 3 & 2.74 & 0.20 & 0.07 & 63.29 & 0.02 & 0.00 & 7.00 & 0.39 & 0.06 \\
\hline NHDPE & 0 & 0 & 0.98 & 0.10 & 0.10 & 28.50 & 0.34 & 0.01 & - & - & \\
\hline NHDPE & 10 & 0 & 1.15 & 0.19 & 0.17 & 32.52 & 0.94 & 0.03 & 5.05 & 0.23 & 0.05 \\
\hline NHDPE & & 3 & 1.40 & 0.08 & 0.06 & 39.56 & 0.44 & 0.01 & 8.06 & 0.21 & 0.03 \\
\hline NHDPE & 20 & 0 & 1.36 & 0.17 & 0.13 & 37.42 & 2.43 & 0.06 & 6.59 & 0.48 & 0.07 \\
\hline NHDPE & & 3 & 2.10 & 0.22 & 0.10 & 49.78 & 1.43 & 0.03 & 5.99 & 0.45 & 0.08 \\
\hline NHDPE & 30 & 0 & 1.94 & 0.14 & 0.07 & 41.82 & 1.41 & 0.03 & 4.51 & 0.34 & 0.08 \\
\hline NHDPE & & 3 & 2.53 & 0.14 & 0.06 & 55.08 & 1.27 & 0.02 & 4.57 & 0.14 & 0.03 \\
\hline NHDPE & 40 & 0 & 2.49 & 0.28 & 0.11 & 47.68 & 4.63 & 0.10 & 3.17 & 0.07 & 0.02 \\
\hline NHDPE & & 3 & 2.97 & 0.24 & 0.08 & 63.26 & 4.21 & 0.07 & 5.30 & 0.37 & 0.07 \\
\hline
\end{tabular}

more linear increase than those with fiber contents of $30 \mathrm{wt} \%$ and higher. The increases were $57.76 \%, 102.15 \%, 115.88 \%$ and $147.64 \%$ for specimens with fiber contents of $10,20,30$ and $40 \mathrm{wt} \%$, respectively.

When the specimens with a CA are compared with those without a CA, the data indicate that for the lowest fiber contents, there was little change: the Young's modulus decreased by $0.90 \%$ and $3.27 \%$ for the specimens with fiber contents of 10 and $20 \mathrm{wt} \%$, respectively. From this point, the Young's modulus increased rapidly, by $9.88 \%$ and $48.15 \%$ for fiber contents of 30 and 40 wt\%, respectively. The increase in the maximum strength with the addition of a CA also improved for fiber contents beyond $20 \mathrm{wt} \%$; the increases were $3.97 \%,-0.51,13.70 \%$ and $14.29 \%$, in the same order as above.

For the HDPE-based biocomposites, the increase in the Young's modulus with the increase in fiber content was irregular. The data indicate increases of $84.01 \%, 119.48 \%, 136.09 \%$ and $266.40 \%$ for the specimens with fiber contents of $10,20,30$ and $40 \mathrm{wt} \%$, respectively. The increase in the maximum stress was non-linear; the corresponding increases were 48.71\%, 70.75\%, 74.02\% and $116.08 \%$, in the same order as above.

The change in the maximum stress with increasing fiber content between the specimens with and without a CA decreased by $21.72 \%, 12.52 \%, 2.24 \%$ and $14.73 \%$ in the same specimen order as above. Additionally, the evolution of the maximum stress became more linear with the addition of the CA. The difference between the maximum stress of each type of specimen with a CA and that of the corresponding specimens without a CA is $-4.35 \%,-1.17 \%$, $9.75 \%$ and $8.15 \%$, in the same specimen order as above.

The data exhibit an interesting trend in the Young's modulus for the NPE green composites. The specimens with fiber contents below 20 wt\% exhibited a lower rate of increase than did the specimens with fiber contents of $30 \mathrm{wt} \%$ or higher. The Young's modulus increased by $16.30 \%, 37.63 \%, 96.67 \%$ and $152.67 \%$, for the specimens with fiber contents of $10,20,30$ and $40 \mathrm{wt} \%$, respectively. The maximum stress increased by $14.11 \%, 31.30 \%, 74.67 \%$ and $67.29 \%$ under the same conditions.
Compared with the corresponding specimens without a CA, the Young's modulus of each type of specimen was increased by $22.59 \%, 55.05 \%, 30.53 \%$ or $19.34 \%$, in the same order as above. The addition of the CA increased the maximum strength of the composite for all fiber contents, with improvements of $24.70 \%$, $43.37 \%, 46.53 \%$ and $54.67 \%$, in the same order as above. CA was most effective at improving the mechanical properties of the green composite.

Overall the mechanical behavior of the three composites (in tensile and flexural testing) is in accordance with similar materials literatures. This behavior can be summarized in three main aspects: (1) the addition of the natural fiber increases the Young modulus and ultimate strength significantly [41]; (2) as expected, the addition of a CA improves substantially the polymer quality resulting in better mechanical properties [42]; and (3) the material becomes brittle with the fiber addition [43]. These observations were valid regardless of the matrix type used, even for NPE based composites.

\section{Acoustic-emission analysis}

\subsection{General degradation behavior in the tensile and flexural tests}

AE tests were performed to investigate microstructural damaging events contributing to the behavior of the biocomposites. The damage was observed through the AE energy parameter. Fig. 3 presents typical examples of the tensile stress curve combined with the plot of the AE cumulative energy versus the strain for all specimens with a fiber content of $30 \mathrm{wt} \%$. The first row represents the LLDPE-based biocomposites, the second represents the HDPE biocomposites, and the last represents the NPE green composites. The column on the left represents samples without a CA, and the column on the right represents samples with a CA.

For the LLDPE, HDPE and NPE composites, various phases are apparent. Initially, no acoustic activity was recorded in the first linear elastic phase. The second phase began when the slope of the 

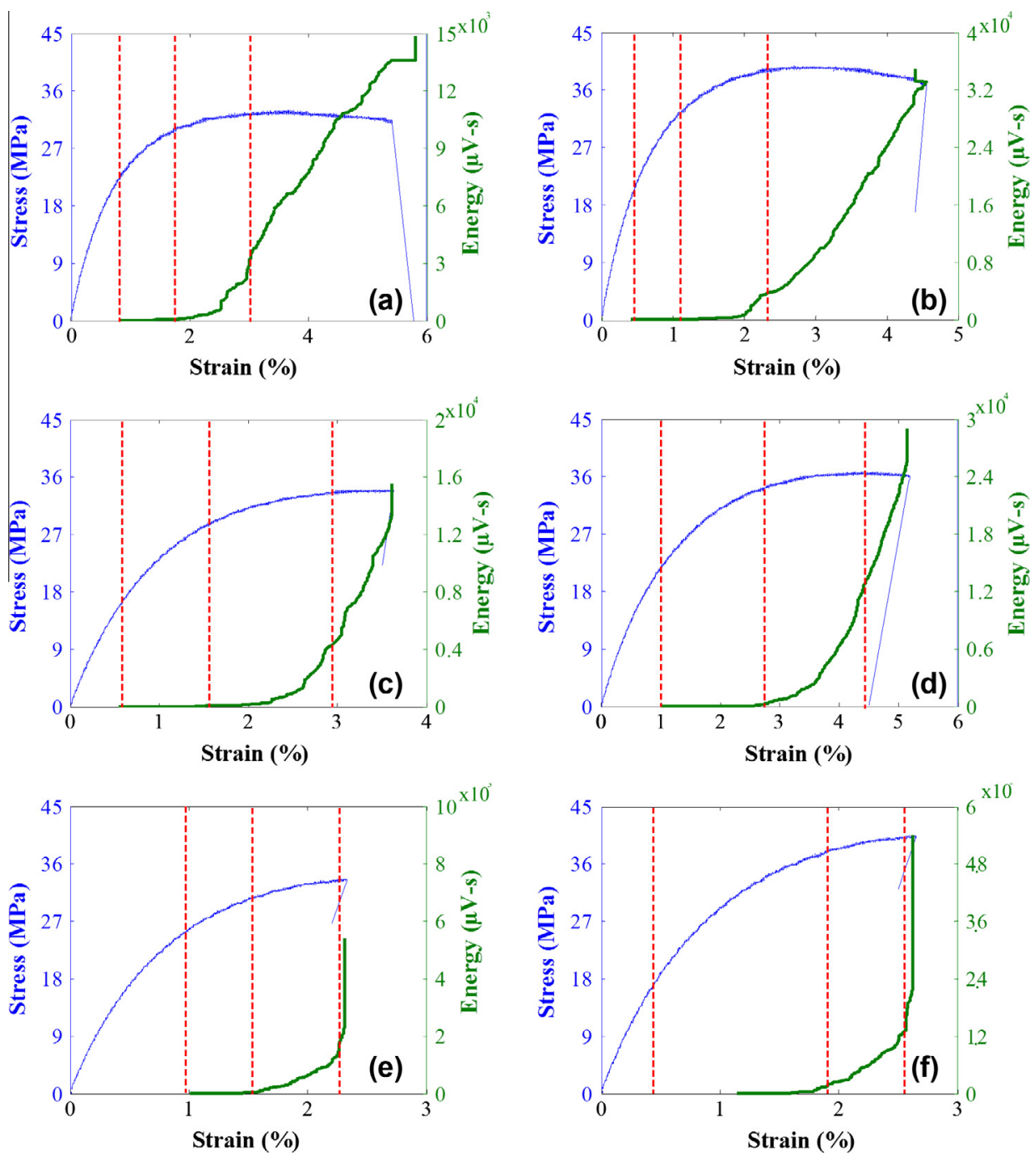

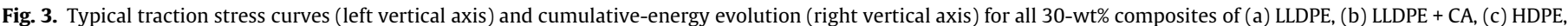
(d) HDPE + CA, (e) NPE and (f) NPE + CA.

stress curve decreased, reflecting the onset of viscoelastic behavior. The onset of the first AE energy measurement is also marked in the figure, at which time the accumulation of AE energy remained low and constant. Third, the evolution of the AE energy curve suddenly became exponential, at which point the stress curve became nonlinear, reflecting the onset of plasticity (inelasticity). This behavior indicated that a new damage mechanism was operating at that point. The fourth phase began near the maximum load, where the evolution of the energy curve changed, exhibiting a nearly linear form until the ultimate breakage of the specimen. Thus, the AE can be correlated with the shape of the stress-strain curve. These four phases could be distinguished in every specimen, with or without CA.

The data show differences among the composites only in the duration of the fourth phase. Because LLDPE is a more ductile matrix than the others, phase 4 continued much longer for the LLDPE-based composites than for the other types of composites. The linear energy-evolution phase indicates that the specimen experienced more internal plastic deformation and damage prior to final failure. The HDPE-based biocomposites exhibited a shorter phase 4 and could sustain less plastic deformation before final failure. The NPE green composites were the most fragile; their phase 4 was very short, and the composites sustained only very low plastic deformation prior to failure.
The same general damage analysis was performed for the flexural testing. Fig. 4 presents the typical energy evolution during flexure in the same order of specimens used in Fig. 3. In the flexural testing, the HDPE and the LLDPE biocomposites exhibited very similar behavior. In the first phase, comprising the elastic linear behavior and the initial drop in the linearity of the strength, the data reflect no AE activity. When the first AE burst was detected, the second phase began, and thenceforth, the AE energy increased constantly, indicating intense plastic deformation around the maximum strength point. The third phase was characterized by a rapid increase in energy prior to final failure.

The NPE green composite behaved completely differently; the data indicate no AE activity in the specimens until near final failure, which was preceded by a rapid increase in activity. No significant difference was perceived in the phase behavior of any composite with the addition of the CA.

\subsection{Correlation of degradation processes with damage modes}

The change in the mechanical properties is often related to a change in the damaging modes. For example, decohesion usually leads to the decrease of composite strength, but decreasing strength is not always associated with poor adhesion and decohesion [44]. For this reason, knowing the mechanical properties and 

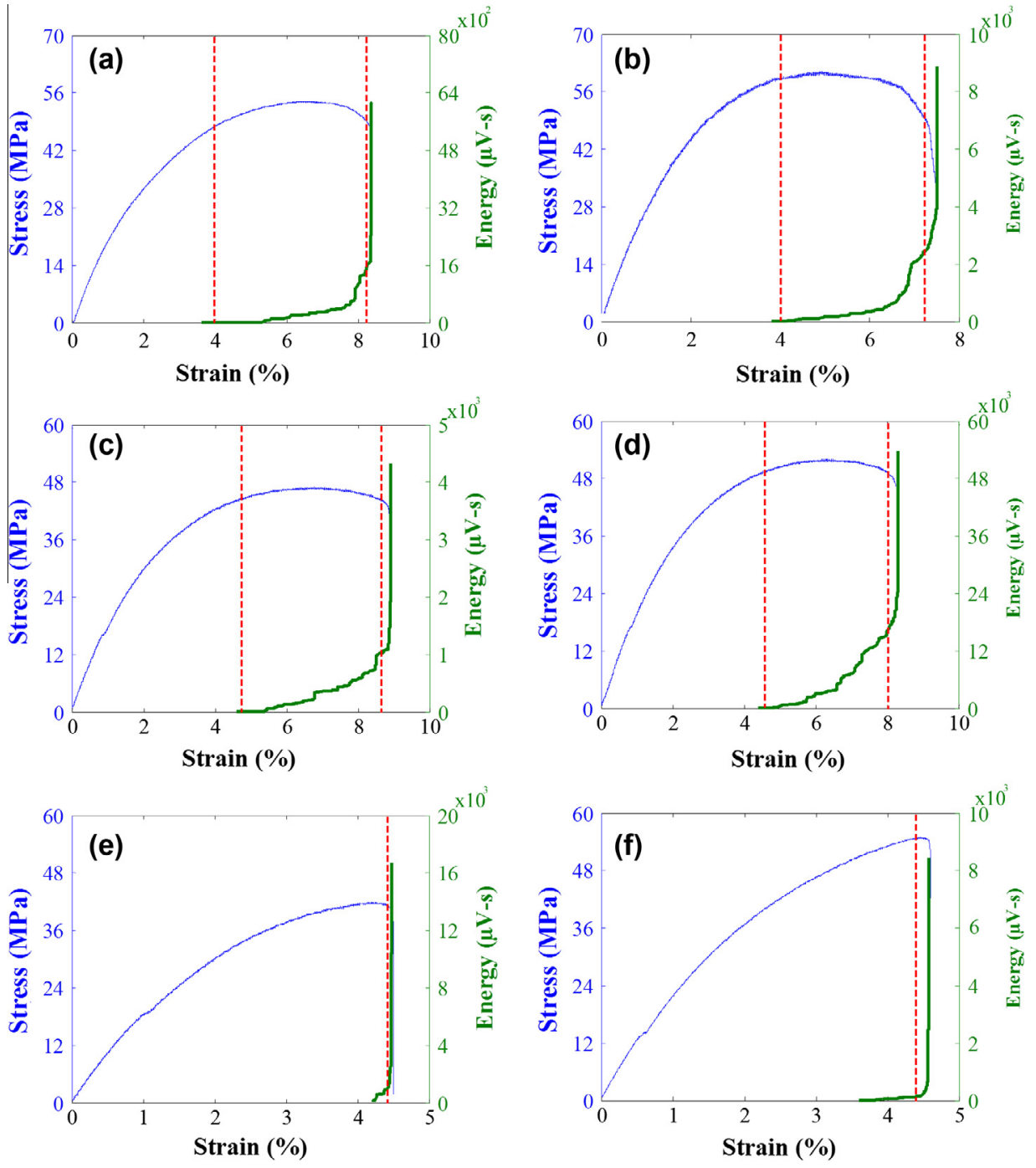

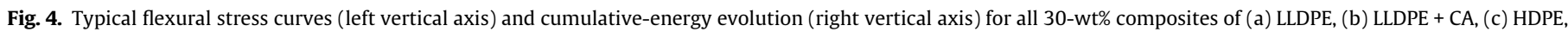
(d) HDPE + CA, (e) NPE and (f) NPE + CA.

general degradation is not sufficient to understand completely the damaging modes.

The AS for damage-mode identification in the PE/birch composite family using of three known parameters (burst amplitude, the counts and the duration) is documented in the literature [34] and it is used in this study for all composites. Table 3 shows the AS values. These values are independent of the fiber weight used [34]. The parameters values are overlapping and the analysis requires a fuzzy logic algorithm for proper mode discrimination.

Typical results of our burst classification are presented alongside the corresponding amplitude and traction curves in Fig. 5 for all 10 -wt\% samples. In this graph, blue points correspond to matrix microcracking, green triangles correspond to matrix/matrix friction, red circles correspond to decohesion between fibers and the

Table 3

Summary of damage acoustical signature [33].

\begin{tabular}{lcrrr}
\hline Damage mode & $\begin{array}{l}\text { Matrix micro- } \\
\text { cracking }\end{array}$ & $\begin{array}{l}\text { Matrix/matrix } \\
\text { friction }\end{array}$ & Decohesion & $\begin{array}{l}\text { Matrix/fiber } \\
\text { friction }\end{array}$ \\
\hline Amplitude $(\mathrm{dB})$ & $35-45$ & $40-55$ & $45-60$ & $55-85$ \\
Duration $(\mu \mathrm{s})$ & $1-80$ & $20-120$ & $50-200$ & $100-600$ \\
Counts & $1-10$ & $8-20$ & $16-35$ & $30-120$ \\
\hline
\end{tabular}

matrix, and black squares correspond to matrix/fiber friction. It is important to note that the fiber length in our specimens was too short (mean length: $0.489 \mathrm{~mm} \pm 0.016 \mathrm{~mm}$ ) for the fiber-breakage mode to occur. The various damage processes observed during the tensile testing of six different $10-w t \%$ composites are depicted in Fig. 5.

The first sign of damage appeared is matrix microcracking in the LLDPE composite without a CA. In the second phase, the curve began to lose its linearity, implying that plastic damage had begun. As the stress, and consequently the strain, increased, the first bursts of matrix/matrix friction appeared. The third phase triggered many decohesion and high-amplitude matrix/fiber friction events around the point of maximum stress. At this point, the stress curve was nonlinear with high levels of plasticity indicated by the internal material frictions of matrix/matrix and matrix/fiber. After passing through a maximum, the stress in the specimen diminished, and in the final phase, there were fewer high-amplitude matrix/fiber bursts.

The corresponding specimen with a CA additive underwent nearly identical damage development, with an additional fragilebreak phase at the end. In general, the amplitudes for the specimen with CA were smaller because the CA reduced decohesion (red bursts) and, consequently, other modes of higher amplitude 

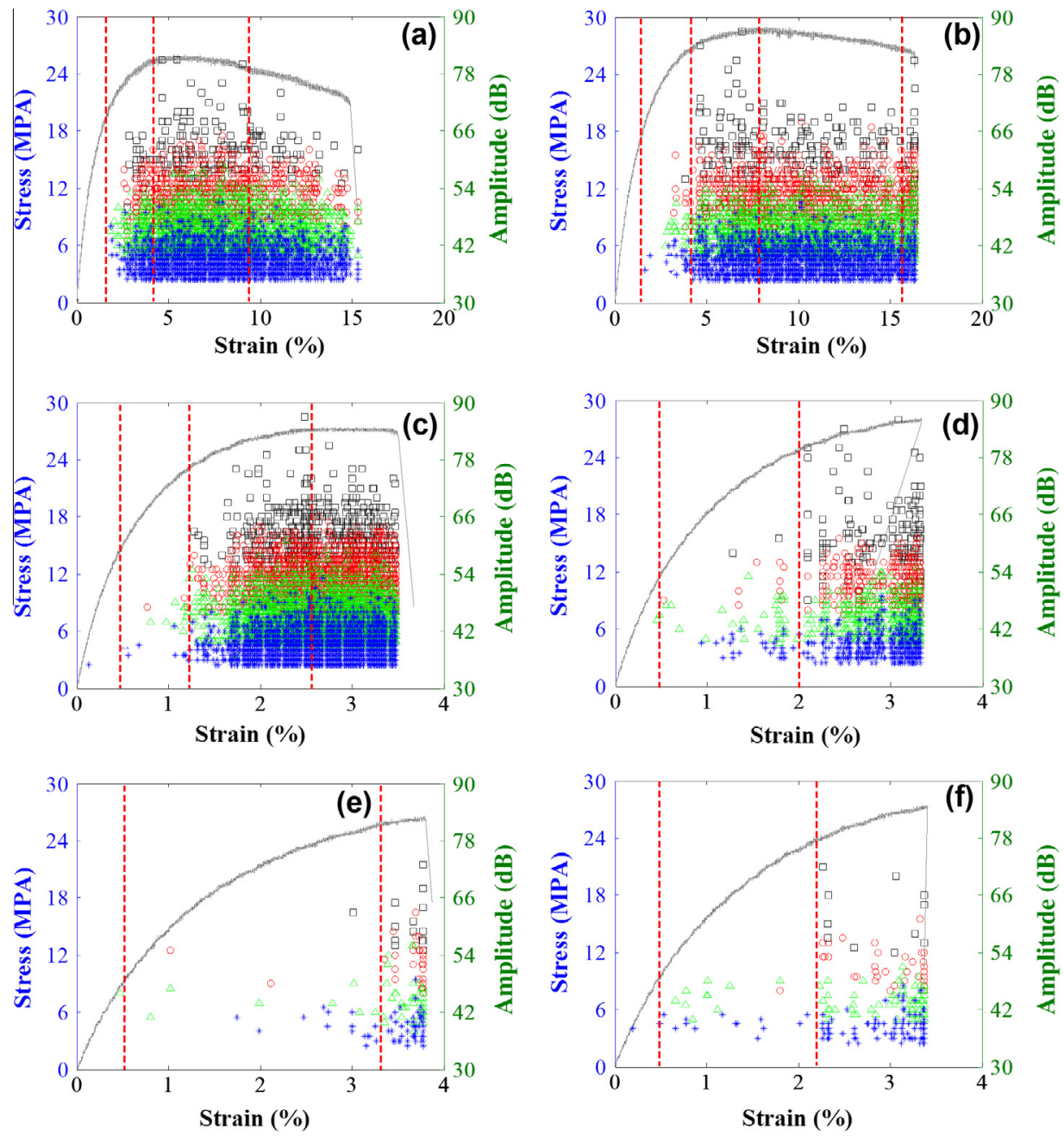

- Matrix microcraking $\triangle$ Matrix/matrix friction $\circ$ Decohesion $\square$ Matrix/fiber friction

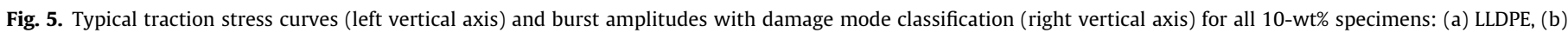
LLDPE + CA, (c) HDPE, (d) HDPE + CA, (e) NPE and (f) NPE + CA.

(matrix/fiber friction). The phases in this specimen tended to begin at lower strain. Phase 4 , which began immediately after the point of maximum stress, exhibited bursts of lower amplitude and continued until immediately prior to final failure. At that moment, a new mechanism arose with high-amplitude events.

The data indicate that the specimen failed differently in phase 5 than in phase 4 , most likely because the matrix had better adhesion to the fiber during the final breakage process.

The data for the HDPE biocomposite without a CA also exhibit four phases. The first phase was linear, without significant $\mathrm{AE}$ events. The second was characterized by the onset of significant matrix microcracking and matrix/matrix friction events, the third by a rapid increase in the $\mathrm{AE}$ event rate and the appearance of decohesion and matrix/fiber friction up to near the point of maximum stress, and the fourth by a decrease in AE activity and matrix/friction amplitude compared with the third phase.

With the addition of a CA, however, the data reflect different behavior. The specimen exhibited three damage phases. In general, the AE events were lower in intensity and frequency. After phase 1 , during which no AE events were recorded, phase 2 began with matrix/matrix friction, not with matrix microcracking as in the specimen without the CA. There were also a few bursts of decohesion and matrix/fiber friction in the first significant AE phase, also differing from the behavior of the specimen without the CA. A rapid increase in decohesion and matrix/fiber friction marked the onset of phase 3 , which continued through a high-burst-amplitude quasi-fragile failure.

In the case of the green composite, the data exhibit completely different behavior once again. With no CA, there were three phases. After the first phase, during which no AE events were recorded, the second phase began with a few low-amplitude events (primarily microcracking and matrix/matrix friction). Phase 3 contained many high-amplitude bursts (decohesion and matrix/fiber friction), resulting in fragile breakage. In general, there were few $\mathrm{AE}$ hits because even at a fiber content of $10 \mathrm{wt} \%$, the specimen broke at a low strain value.

With the addition of $3 \mathrm{wt} \% \mathrm{CA}$, breakage still occurred, but phase 3 was longer. This finding might be related to the fact that the specimens were made more resistant by the addition of a CA. Nonetheless, the low burst number is still an indication that the material was very fragile. Apart from the completely different damaging process, however, there was only a small difference in the mechanical properties of the HDPE and NPE composites. This finding indicates that the choice of a composite for a particular application must be judicious and should take into account not only the mechanical properties but the damage processes of the 
composite, which may be crucial for long-term applications. The NPE green composites were found to be much more fragile and more likely to suffer sudden complete failure than the HDPE or LLDPE biocomposites.

Fig. 6 reproduces the same typical graphs as in Fig. 5 for the flexural testing of the 10 -wt\% specimens. In the flexural tests, a given specimen did not present the same phases as in the tensile test. In the case of the LLDPE-based composites, both with and without the addition of the CA, only a few bursts were detected in phase 2. The following phase exhibited a higher hit frequency and three dominating modes (matrix microcracking, matrix/matrix friction and decohesion); this phase coincided with the point at which the stress curve passed through the point of maximum stress. In the subsequent phase, although the stress decreased, the burst amplitudes increased and the first evidence of matrix/ fiber friction was observed. Unlike the tensile testing data, these data indicate that the use of a CA did not affect the damage modes during flexural testing. The HDPE-based biocomposites behaved similarly to the LLDPE-based biocomposites, i.e., the same phases appeared, and the phases remained the same regardless of the use of a CA.

The damage behavior of the green composites, however, was surprising. There were only two phases in the case of the NPE composite without the CA. This is due to the fact that NPE is a brittle material and the of CA results in a poor fiber adhesion. A large number of bursts were recorded immediately prior to the final fragile breakage, and no damage events were observed up to that point. With the CA addition, the adhesion between matrix and fiber is improved in a way that the load is better transferred to the fiber. In this manner the stress in the matrix itself decreases and an intermediate second phase occurs with small intensity matrix related damages. This phase is observed after a first phase with no burst. When the interface between matrix and fiber is broken with first decohesion damage, the load supported by the fiber is rapidly transferred to the matrix starting a brittle process of catastrophic failure.

\subsection{Analysis of the contribution of each damage mode}

To evaluate the extent of the damage caused by each mode and its contribution to the overall failure, we used the damage participation index, which is defined as follows:

$D_{j}=\frac{E_{j}}{\sum_{j=1}^{4} E_{j}}$

where $D_{j}$ is the damage index for mode $j$ and $E_{j}$ is the energy of mode $j$.
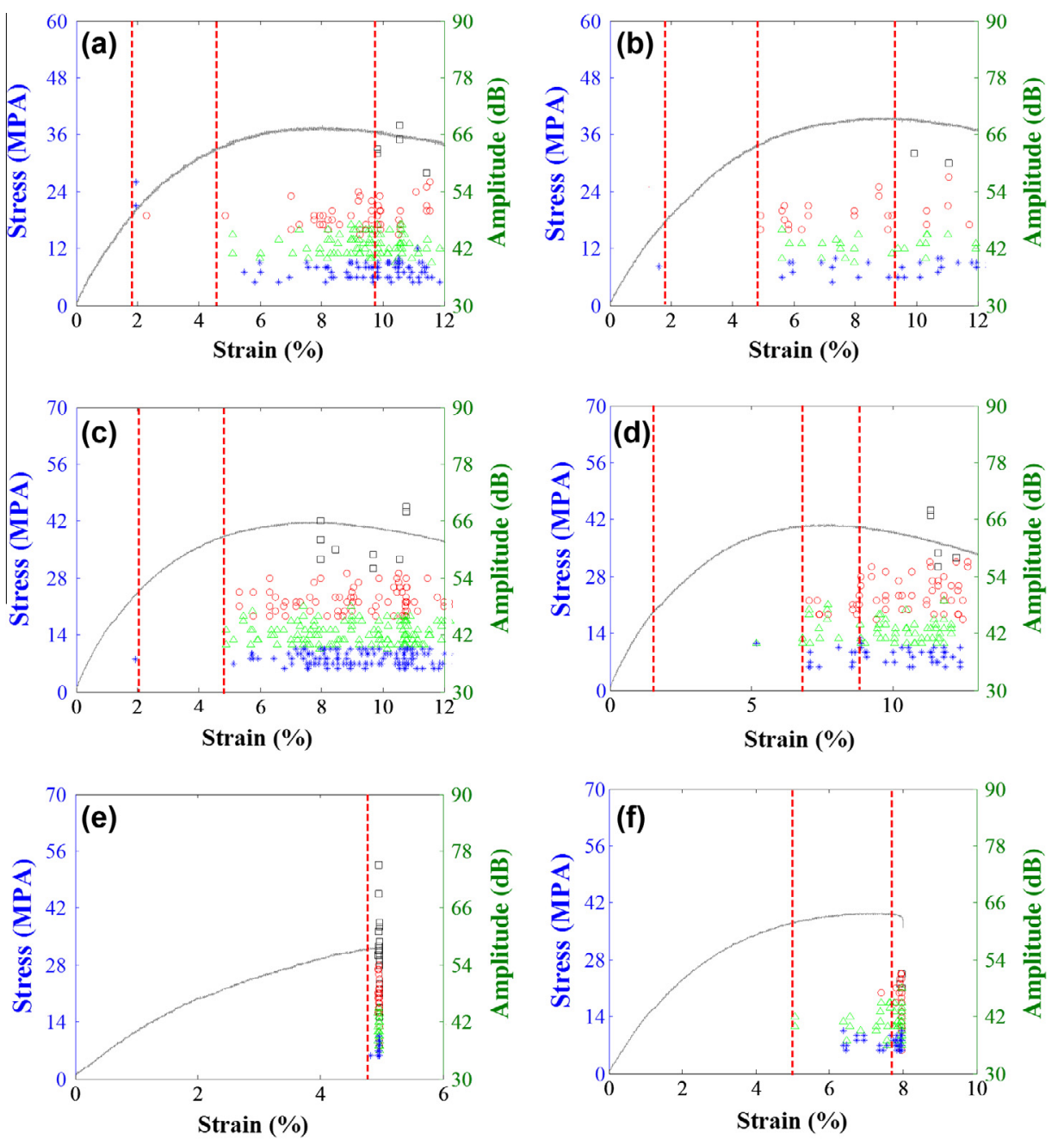

- Matrix microcraking $\Delta$ Matrix/matrix friction $\circ$ Decohesion $\square$ Matrix/fiber friction

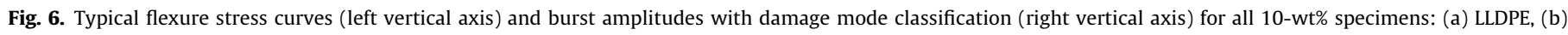
LLDPE + CA, (c) HDPE, (d) HDPE + CA, (e) NPE and (f) NPE + CA. 
The same specimens investigated in the previous section were used to analyze the phases of the general degradation behavior, i.e., specimens of $30 \mathrm{wt} \%$ fiber content were used to study the details of the damage process. In Fig. 7, it is evident that the most significant energy mode in the LLDPE biocomposite without a CA was matrix/fiber friction (34,5\%), which was also the most significant energy mode in the sample with a CA (36.7\%). The second most damaging mode varied with the use of a CA. In the specimen without a CA, the second most damaging mode was decohesion (32.4\%), whereas the third was matrix/matrix friction (28.0\%). However, with the addition of CA, the order reversed; the second most damaging mode became matrix/matrix friction (30.2\%), and the third became decohesion (27.1\%). The fourth most damaging mode in both cases was matrix microcracking, with $5.1 \%$ participation without CA and $6.1 \%$ with CA. These changes (especially the reduced decohesion) indicate that the $C A$ played a significant role in determining the fracture modes.

The order of importance of the modes was not the same in the HDPE biocomposites. The most damaging mode in the composite without a CA was decohesion (44.2\%), and the second most damaging mode was matrix/fiber friction (29.2\%). This order was reversed by the addition of a CA, i.e., the most significant mode became matrix/fiber friction (38.5\%), followed by decohesion (32.1\%). This result illustrates the active role played by the CA in fiber/matrix adhesion. The third most damaging mode (matrix/matrix friction: $22.0 \%$ without CA, $24.7 \%$ with CA) and the fourth (matrix microcracking: $4.5 \%$ without $C A, 4.6 \%$ with $C A$ ) remained the same regardless of CA use.

With respect to the NPE green composites, the most significant damage mode in the specimen without a CA was decohesion (44.8\%), whereas with a CA, it was matrix/matrix friction (53.3\%).
The second most damaging mode with a CA was decohesion (25.8\%), and without a CA, it was matrix/matrix friction (35.4\%). These results indicate that MAPE was an effective CA even for the new green composite. Importantly, this finding demonstrates that there is no immediate need for the development of a novel CA for use in NPE green composites. The third most damaging mode in the specimen without a CA was matrix/fiber friction (12.7\%). In the specimen with a CA, however, the third most important mode was matrix microcracking, with $14.1 \%$ participation; it was the sole specimen for which this mode was not the fourth most important.

During flexural testing (Fig. 8), the mode-participation results were different from those observed during tensile testing. In the LLDPE biocomposites, the most important mode was decohesion, with $44.4 \%$ participation for the specimen without a CA and $42.3 \%$ for that with a CA. The reduction in the amount of decohesion with the addition of a CA demonstrates the latter's effectiveness. The second most damaging mode was matrix/fiber friction: $30.7 \%$ without a CA and $34.1 \%$ with a CA. The third was matrix/ matrix friction ( $23.8 \%$ without a CA and $23.2 \%$ with a CA). Contrary to the results of tensile testing, the addition of the CA did not affect the order of mode importance during flexural testing for this biocomposite.

For the HDPE composites, the most damaging mode was decohesion, with $50.2 \%$ participation without a CA and $42.2 \%$ with a CA. Again, the CA was effective reducing decohesion between the fibers and the matrix. The second most damaging mode was matrix/matrix friction, with $41.4 \%$ participation without a CA and $34.2 \%$ with a CA. The third was matrix/fiber friction, which was stronger in the specimen with a CA $(22.4 \%)$ than in that without a CA (5.6\%). The matrix microcracking mode was the least effective

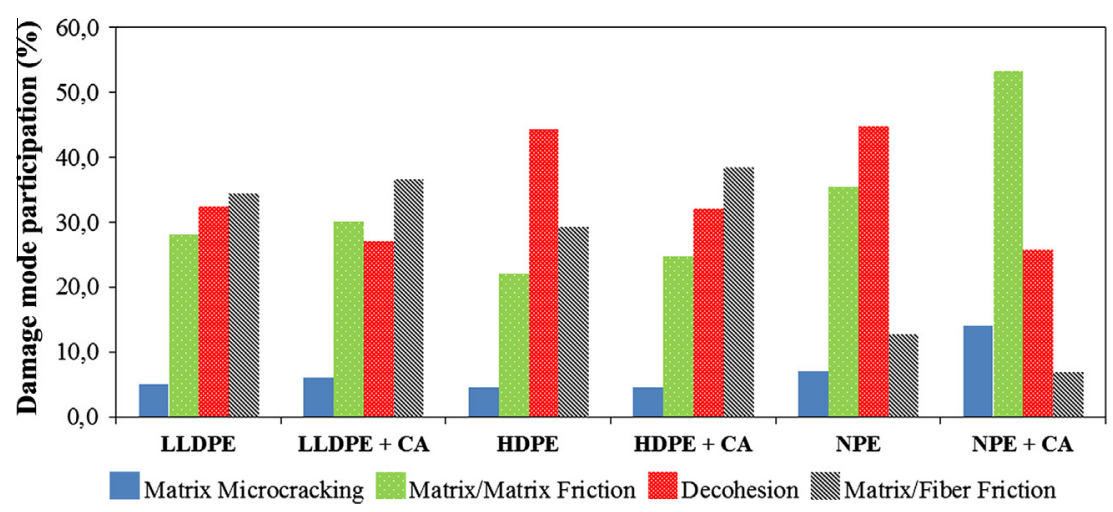

Fig. 7. Damage-mode participation for $30-w t \%$ specimens during tensile testing.

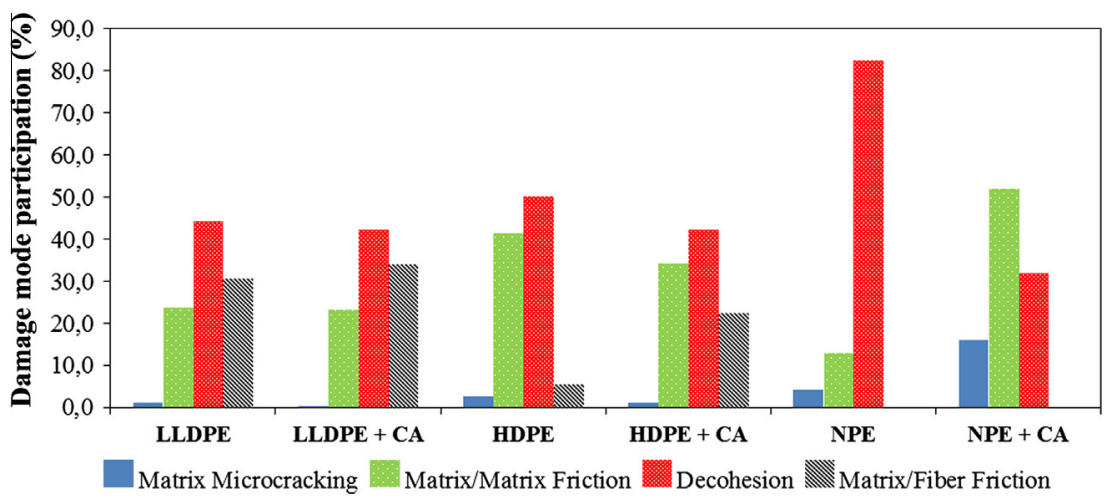

Fig. 8. Damage-mode participation for $30-w t \%$ specimens during flexural testing. 
damage mode in all HDPE-based specimens regardless of the test performed.

In the case of the NPE green composite without a CA, decohesion was by far the most important mode in the damaging process (82.6\%), followed matrix/matrix friction $(13.0 \%)$ and then matrix microcracking as the third (4.3\%). No evidence of matrix/fiber friction was observed. In the specimen with a CA, however, the major driver of the damaging process was matrix/matrix friction (52.0\%), illustrating yet again the effective interaction of MAPE with the green matrix. This result corroborates the findings of the tensile testing and has important scientific and economic consequences: the CA currently in use can be used for both normal PE and the new NPE. For the NPE green composite with a CA, the second most damaging mode was decohesion (31.9\%), and the third was matrix microcracking (16.1\%). Again, no fiber/matrix friction was detected. We can conclude that the damage-mode participation depends on the material, the test performed and, especially, the presence of a CA that improves the fiber/matrix adhesion.

\section{Fractured-surface SEM images}

Images of a fractured surface of metalized specimens obtained using SEM can reveal the primary cause of failure. In this section, we present the results of analyzing two tensile test cases: (1) the difference between corresponding HDPE and NPE biocomposites without CA and (2) the difference caused by preparing an LDPE biocomposite with and without a CA.

In the first case, we compared samples with a fiber content of $30 \mathrm{wt} \%$. Fig. 9a shows the state of the surface of the HDPE-based composite without a CA at a magnification of $100 \times$. It is possible to observe some twists and bended material at the matrix level. This is a sign of plasticity or permanent material deformation. Fig. 9a and b presents holes on the surface (indicated with arrows) indicating that fibers were pulled out. This is an indication that the adhesion between matrix and fiber were probably poor.

An image of the fractured surface of the NPE green composite is presented in Fig. 9c-d. Matrix deformation has begun in the upperleft region of the image presented in Fig. 9c (at $100 \times$ ), whereas in the rest of the image, the surface appears flat. This indicates that the total rupture of the matrix occurred after an initial deformation. This fracture was so brutal that it left a cut-like formation on the surface, as seen in Fig. 9d (at 500×), which corresponds to the fragile fracture indicated by the $\mathrm{AE}$ results.

Fig. 10 illustrates the difference between an LLDPE-based biocomposite with a CA and one without a CA at $30 \mathrm{wt} \%$ fiber content. The fractured-face micrograph presented in Fig. 10a is of a 30 -wt\% specimen without a CA at a magnification of $250 \times$ (a compromise between a detailed and a general view). The image shows a matrix with fiber voids. The image in Fig. 10b shows the corresponding specimen with the addition of $3 \mathrm{wt} \% \mathrm{CA}$. There are no visible fiber voids, and it is evident that the fibers
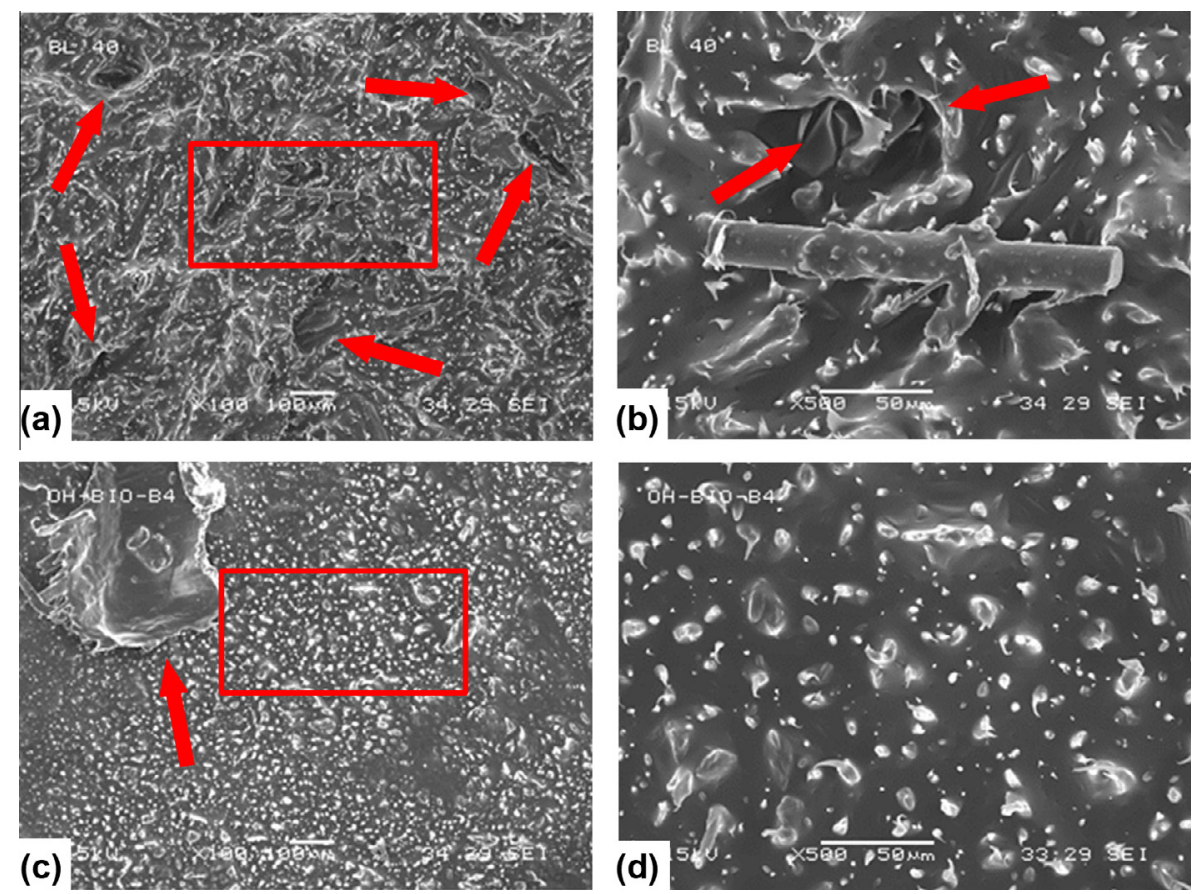

Fig. 9. (a and b) HDPE composite at 30 wt\% fiber content without a CA. (c and d) NPE green composite at 30 wt\% fiber content without a CA.

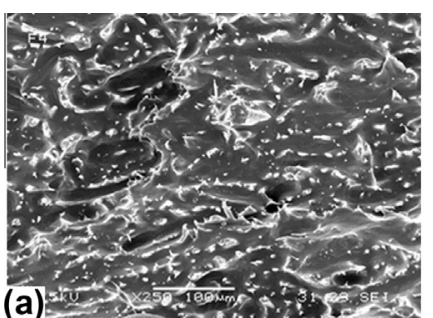

(a)

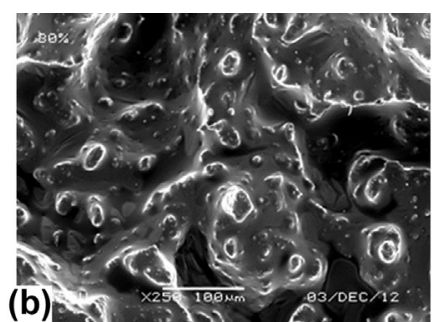

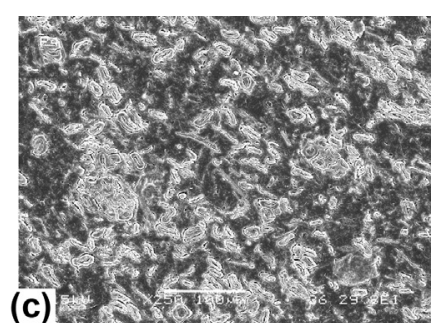

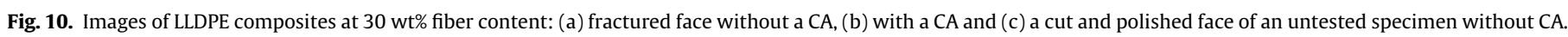


remained fixed in the matrix after the final failure. This behavior was the result of better fiber/matrix interface and less decohesion, as also evidenced by the AE results. These damage mechanisms are more evident when the fractured faces are compared to a cut and polished surface of an untested 30-wt\% specimen without a CA at a magnification of $250 \times$ (Fig. 3c). In this image we can see the mix matrix (dark gray) with embedded fibers (light gray).

\section{Conclusions}

Monotonic tensile and 3-point flexural tests were conducted to investigate the mechanical properties, the evolution and damage mechanisms using AE testing. The mechanical results showed that NPE has a better interaction with the natural fibers with a remarkable improvement in the mechanical properties, especially when CA was added.

The damage was measured using the AE energy parameter. During tensile testing, the LLDPE, HDPE and NPE composites exhibited four phases. The most noticeable differences were in the duration of the fourth phase. This phase was characterized by many AE events caused by plastic deformation. NPE based composite had a sudden rupture with few bursts prior to the failure.

AE-based damage-mode identification indicated that the participation of decohesion in the specimens damage was reduced by the use of CA. It was concluded that damage participation depends on the material, the test itself and, especially, the presence of a CA that improves the fiber/matrix adhesion. The current used CA used for PE has the same effectiveness when used with NPE.

The results of this study are compelling and were independently confirmed by SEM images of the tensile fractured faces of the specimens, which revealed the primary causes of material failure. The choice of a composite for a particular application must be judicious and should consider not only the mechanical properties, which may be similar for different materials, but also the various damage processes and their relative importance, which may be completely different for different materials and may be crucial for long-term applications.

\section{Acknowledgement}

The authors would like to acknowledge the financial support of the Natural Sciences and Engineering Research Council (NSERC) of Canada.

\section{References}

[1] Khan MA, Masudul Hassan M, Drzal LT. Effect of 2-hydroxyethyl methacrylate (HEMA) on the mechanical and thermal properties of jute-polycarbonate composite. Compos A Appl Sci Manuf 2005;36:71-81.

[2] Lee SG, Choi SS, Park WH, Cho D. Characterization of surface modified flax fibers and their biocomposites with PHB. In: Macromolecular symposia; 2003. p. $089-100$.

[3] Nkwachukwu OI, Chima CH, Ikenna AO, Albert L. Focus on potential environmental issues on plastic world towards a sustainable plastic recycling in developing countries. Int J Ind Chem 2013;4:1-13.

[4] EL Little J. Checklist of United States trees (native and naturalized). Agriculture Handbook, UK Department of Agriculture; 1979.

[5] G'SELL C. Plasticité et endommagement des polymères structuraux. L'Actualité chimique 2002:40-3.

[6] Gu R, Kokta BV, Michalkova D, Dimzoski B, Fortelny I, Slouf M, et al. Characteristics of wood-plastic composites reinforced with organonanoclays. J Reinf Plast Compos 2010;29:3566-86.

[7] Raj R, Kokta B, Maldas D, Daneault C. Use of wood fibers in thermoplastics. VII. The effect of coupling agents in polyethylene-wood fiber composites. J Appl Polym Sci 1989;37:1089-103.

[8] Mijiyawa F, Koffi D, Kokta B, Erchiqui F, Toubal L. Renforcement des thermoplastiques par les fibres de bois pour une application aux engrenages: prédiction du module élastique en traction. In: Presented at the Journées Nationales sur les Composites JNC 18, Nantes-France; 2013.
[9] Mijiyawa F, Koffi D, Kokta B, Erchiqui F. Effects of wood fibers on tensile properties, wettability and thermal degradation behaviour of polyethylenewood composites. In: Presented at the 29th international conference of the polymer processing society (PPS-29) Nuremberg, Germany; 2013.

[10] Lafia-Araga RA, Hassan A, Yahya R, Rahman NA, Hornsby PR, Heidarian J. Thermal and mechanical properties of treated and untreated Red Balau (Shorea dipterocarpaceae)/LDPE composites. J Reinf Plast Compos 2012;31:215-24.

[11] Nourbakhsh A, Kokta BV, Ashori A, Jahan-Latibari A. Effect of a novel coupling agent, polybutadiene isocyanate, on mechanical properties of wood-fiber polypropylene composites. J Reinf Plast Compos 2008;27:1679-87.

[12] Nourbakhsh A, Ashori A, Kouhpayehzadeh M. Giant Milkweed (Calotropis persica) Fibers-a potential reinforcement agent for thermoplastics composites. J Reinf Plast Compos 2009;28:2143-9.

[13] Bera M, Alagirusamy R, Das A. A study on interfacial properties of jute-PP composites. J Reinf Plast Compos 2010;29:3155-61.

[14] Földes E, Iring M, Tüdős F. Degradation of HDPE and LLDPE in closed mixing chamber: a comparison. Polym Bull 1987;18:525-32.

[15] Shirayama K, Kita SI, Watabe H. Effects of branching on some properties of ethylene/ $\alpha$-olefin copolymers. Die Makromolekulare Chemie 1972;151:97-120.

[16] Arieby R. Caractérisation mécanique et modélisation thermodynamique du comportement anisotrope du polyéthylène à haute densité. Intégration des effets d'endommagement," Intégration des effets d'endommagement. Doctorat mécanique et energétique, Institut National Polytechnique de Lorraine; 2007.

[17] Migneault S, Koubaa A, Erchiqui F, Chaala A, Englund K, Krause C, et al. Effect of fiber length on processing and properties of extruded wood-fiber/HDPE composites. J Appl Polym Sci 2008;110:1085-92.

[18] Raj R, Kokta B. Reinforcing high density polyethylene with cellulosic fibers. I: the effect of additives on fiber dispersion and mechanical properties. Polym Eng Sci 1991;31:1358-62.

[19] Lu JZ, Wu Q, Negulescu II. Wood-fiber/high-density-polyethylene composites: coupling agent performance. J Appl Polym Sci 2005;96:93-102.

[20] Colom X, Carrasco F, Pages P, Canavate J. Effects of different treatments on the interface of HDPE/lignocellulosic fiber composites. Compos Sci Technol 2003:63:161-9.

[21] Adhikary KB, Pang S, Staiger MP. Dimensional stability and mechanical behaviour of wood-plastic composites based on recycled and virgin highdensity polyethylene (HDPE). Compos B Eng 2008;39:807-15.

[22] Luo S, Netravali A. Interfacial and mechanical properties of environmentfriendly "green" composites made from pineapple fibers and poly (hydroxybutyrate-co-valerate) resin. J Mater Sci 1999;34:3709-19.

[23] Fernandez MF, Ozkalustyan MLV, Camargo A, Nascimento PT, Yu A. Bio-based plastics evolution and the challenges to achieve dominance. In: Technology management in the IT-driven services (PICMET), 2013 proceedings of PICMET'13; 2013. p. 2726-34.

[24] Braskem. Green polyethylene biopolymer, innovation transforming plastic into sustainability; 2010.

[25] Phillips AL. Bioplastics boom. Am Sci 2008;96:109-10.

[26] De Almeida Oroski F, Chaves Alves F, Bomtempo JV. Bioplastics Tipping Point: drop-in or non-drop-in? J Bus Chem 2014;11

[27] Máthis K, Chmelík F. Exploring plastic deformation of metallic materials by the acoustic emission technique. Acoustic Emission, InTech, Rijeka2012; 2012. p. 23-48.

[28] Kachanov L. Time of the rupture process under creep conditions. Isv Akad Nauk SSR Otd Tekh Nauk 1958;8:26-31.

[29] Mehan R, Mullin J. Analysis of composite failure mechanisms using acoustic emissions. J Compos Mater 1971;5:266-9.

[30] Kotsikos G, Evans J, Gibson A, Hale J. Use of acoustic emission to characterize corrosion fatigue damage accumulation in glass fiber reinforced polyester laminates. Polym Compos 1999;20:689-96.

[31] Laksimi A, Benmedakhene S, Bounouas L. Monitoring acoustic emission during tensile loading of thermoplastic composites materials. In: Proceeding of ICCM; 1999.

[32] Liu P, Chu J, Liu Y, Zheng J. A study on the failure mechanisms of carbon fiber/ epoxy composite laminates using acoustic emission. Mater Des 2012:37:228-35.

[33] Henriksson M, Berglund LA, Isaksson P, Lindström T, Nishino T. Cellulose nanopaper structures of high toughness. Biomacromolecules 2008;9:1579-85.

[34] Bravo A, Toubal L, Koffi D, Erchiqui F. Characterization of tensile damage for a short birch fiber-reinforced polyethylene composite with acoustic emission. Int J Mater Sci 2013;3.

[35] Ganguli R. A fuzzy logic system for ground based structural health monitoring of a helicopter rotor using modal data. J Intell Mater Syst Struct 2001;12:397-407.

[36] Mylvaganam S. Some applications of acoustic emission in particle science and technology. Part Sci Technol 2003;21:293-301.

[37] Loutas T, Sotiriades G, Kalaitzoglou I, Kostopoulos V. Condition monitoring of a single-stage gearbox with artificially induced gear cracks utilizing on-line vibration and acoustic emission measurements. Appl Acoust 2009;70:1148-59.

[38] Omkar S, Suresh S, Raghavendra T, Mani V. Acoustic emission signal classification using fuzzy C-means clustering. In: Neural information processing, 2002. ICONIP'02. Proceedings of the 9th international conference on; 2002. p. 1827-31. 
[39] Deepthi M, Sharma M, Sailaja R, Anantha P, Sampathkumaran P, Seetharamu S. Mechanical and thermal characteristics of high density polyethylene-fly ash Cenospheres composites. Mater Des 2010;31:2051-60.

[40] Jemielniak K. Some aspects of acoustic emission signal pre-processing. J Mater Process Technol 2001;109:242-7.

[41] Arrakhiz F, El Achaby M, Malha M, Bensalah M, Fassi-Fehri O, Bouhfid R, et al. Mechanical and thermal properties of natural fibers reinforced polymer composites: Doum/low density polyethylene. Mater Des 2013;43:200-5.

[42] Pérez-Fonseca A, Robledo-Ortíz J, Ramirez-Arreola D, Ortega-Gudiño P, Rodrigue D, González-Núñez R. Effect of hybridization on the physical and mechanical properties of high density polyethylene-(pine/agave) composites. Mater Des 2014:10.

[43] AlMaadeed MA, Nogellova Z, Mičušík M, Novak I, Krupa I. Mechanical, sorption and adhesive properties of composites based on low density polyethylene filled with date palm wood powder. Mater Des 2014;53:29-37.

[44] Faludi G, Link Z, Renner K, Móczó J, Pukánszky B. Factors determining the performance of thermoplastic polymer/wood composites; the limiting role of fiber fracture. Mater Des 2014;61:203-10. 